\title{
Diversity of Airborne fungal in Thanjavur District, Tamil Nadu, India
}

\section{O.N.Shanmugapriya and S.Priya*}

P.G and Research Department of Microbiology, S.T.E.T. Women's College, Mannargudi, T.Nadu, India

P.G Department of Biotechnology, S.T.E.T. Women's College, Mannargudi, T.Nadu, India Corresponding Author: piri_333@yahoo.co.in, +919787392903

\section{ABSTRACT}

Airborne fungal spores constitute one of the important components of microbial population of ambient air. Aeromycological study was conducted for two years (January, 2012 to December, 2013) using Rotorod air sampler in the indoor air of certain residential dwellings in Thanjavur District, Tamil Nadu, India. During the present investigation, 15 fungal types were detected of which Trichoderma spores contributed highest concentration. Maximum concentration of fungal spores was observed in the month of August in 2012 and November in 2013 while minimum concentration was observed in the month of September in both years. Allergenically significant fungal spores responsible for serious health hazards were detected throughout the investigation period. Seasonal variation of airborne fungal spores was correlated with meteorological parameters.

Keywords: Allergy; indoor aerobiology; meteorological parameters; seasonal variation.

\section{Council for Innovative Research}

Peer Review Research Publishing System

Journal of Advances in Natural Sciences

Vol. 3, No. 1

editorjansonline@gmail.com

www.cirworld.com 


\section{INTRODUCTION}

Fungi, especially filamentous fungi, which are common aeroallergens, form a major part of bioaerosols. Fungi are ubiquitous in outdoor air, and their concentrations, aerodynamic diameters and taxonomic compositions have potentially important implications for human health (Agarwal and Shivpuri,1974) .

The diversity and abundance of anemophilous microorganisms can be influenced by and can interfere with environmental conditions. These microorganisms are influenced by factors such as season, temperature, the relative humidity of the air and other parameters that exhibit seasonal variation (Gravesen, 1972). The relationships among allergic exposure, the fungal presence in indoor and outdoor environments and consequent allergic diseases are not fully understood. Therefore, it is important to know both the frequency of certain airborne fungi and their distributions according to the season and the main environment (i.e., indoor or outdoor) in order to evaluate their correlations with respiratory symptoms related to allergic processes (Tilak and Babu, 1983).

These fungi can be used to assess effects on the environment and could contribute to determining the principal changes. The spores of fungi can be present in air particles and can potentially influence the hydrological cycle and climatic changes (Greicy Kiel et al., 2007). In addition, humans are exposed daily to bioaerosols in their personal and professional lives, and these airborne particles represent a potential biological occupational hazard. Biological particles in the air are approximately $40 \%$ organic carbon by mass and can be an important source of bioaerosols in the atmosphere above continents (Morales et al., 2006).

In Thanjavur district, peoples are actively engaged in the field of aerobiology using various techniques with reference to airspora inside bakery, hostel kitchen, saw mill, rice mill, library, rice grains store cum sale shops, cowshed, etc. besides airspora of field crops (Adhikari et al., 1996). So far, no work has been done on the fungal airspora of residential dwellings of Thanjavur. In the light of the above facts, the present investigation was undertaken to detect the components of fungal airspora, their seasonal variations and possible sources from the indoor air of residential dwellings in Thanjavur District, Tamil Nadu, India.

\section{MATERIALS AND METHODS}

Monitoring of indoor fungal airspora was carried out in three dwelling houses at Thanjavur for two consecutive years (January, 2012 to December, 2013) by employing Tilak's rotorod air sampler. Transparent cellotape was applied to the rods of the sampler, trimmed back to the width of the rods and coated with Vaseline (Devi et al., 2012) . The sampler was operated at weekly intervals twice a day (9.30 to 10 a.m. and 4.30 to 5 p.m.) by keeping at a height of 1 metre above ground level. Slides were prepared using glycerine jelly mountant and scanned regularly. The spore count was multiplied by the conversion factor, 5 . The spores so trapped were identified based on morphological characters (Ayangbimpe et al., 2010), visual identification by comparison with reference slides, published literatures and culture plate identifications. During the investigation period, meteorological parameters were obtained from Harman Research Centre, Thanjavur.

\section{RESULTS AND DISCUSSION}

Airborne spores detected were presented under two categories - fungal spores and other types. Altogether 15 fungal types were identified and grouped as fungal spores while epidermal hairs, insect scales, Mycelial fragments and unidentified types, etc. were grouped as other types (Banerjee et al., 1987). Fungal spores contributed 99.54\% and other types contributed $0.46 \%$ of the total airspora. The present result revealed wide range coverage of taxonomic composition of fungal spores. The abundance and frequency of different spores were presented in Table -1 . The dominant fungal types scoring $100 \%$ abundance during the present study were Alternaria, Basidiospores, Chaetomium, Cladosporium, Fusarium, Helminthosporium, Nigrospora, Periconia, round spores (Rhizopus-Mucor type), Sclerotium, Trichoderma and other types. Similar results were reported by previous workers. Among the fungal types, Trichoderma contributed highest concentration $(28.73 \%)$ which was followed by Fusarium (14.13\%), round spores (Rhizopus-Mucor type)(12.41\%), Cladosporium (11.74\%), Chaetomium (6.85\%), (5.37\%), Curvularia (4.85\%), Basidiospores (4.79\%), Alternaria (4.63\%), etc. The finding was in agreement with other reports (Noble and Clayton,1963).

During 2012, the highest $(3.50 \%)$ spore catch was observed on the 30th August which corresponds to temperature $\left(\max .30 .5^{\circ} \mathrm{C}\right.$ and $\left.\mathrm{min} .25 .0^{\circ} \mathrm{C}\right)$, relative humidity $(80 \%)$ and rainfall $(4.0 \mathrm{~mm})$ and the lowest $(0.25 \%)$ spore catch was observed on the 12th September which corresponds to temperature (max.26.60C and min.16.50C), relative humidity (41.5\%) and rainfall (nil) whereas during 2013 , the highest $(2.41 \%)$ spore catch was observed on the 17 th November which corresponds to temperature (max. $25.3^{\circ} \mathrm{C}$ and $\min .20 .8^{0} \mathrm{C}$ ), relative humidity $(75.1 \%)$ and rainfall $(80 \%)$ and the lowest $(0.45 \%)$ spore catch was observed on the 25th September which corresponds to temperature (max. $30.60 \mathrm{C}$ and min. $19.30 \mathrm{C})$, relative humidity $(65 \%)$ and rainfall $(75 \%)$. The present finding clearly showed that the concentration of fungal spores have seasonal variations. From the perusal of the above analysis, it was clear that there was a wide range of variations in relative humidity in between the distribution of highest and lowest concentration of airspora. Thus, showed that there was a close correlation between meteorological factors and the concentration of airspora. The present result also emphasized the associate effect of meteorological and other artificial factors like availability of substrates, disturbance of substrates due to sweeping, cleaning, repairing works, etc. and infiltration of airspora from outdoor environments. The finding was in agreement with that of other workers (Baitule SJ. and Saoji,2002) .

During the present investigation, it was observed that a large number of fungi, viz. Aspergillus, Mucor, Rhizopus, Trichoderma, Cladosporium, Epicoccum, Fusarium, Curvularia, Chaetomium, etc. were present which were known to be associated with respiratory and allied allergy. Significant mould allergen from similar environment was reported by other workers ${ }^{11}$. The role of different sources and their contribution to the total airspora inside the house with reference to dust 
vegetable remains, patches attached on surface, corner, wall, etc. have reflected a large number of fungal types, viz. Aspergillus, Fusarium, Curvularia, Chaetomium, Sclerotium, Trichoderma, etc. The present finding was in agreement with the previous reports.It was evident from the present finding that the existence of airborne fungal biopllutants qualitatively and quantitatively as well as fluctuations in their occurrence were definitely controlled by meteorological factors besides the presence of abundant substrates in the indoor environment

\section{CONCLUSION}

The literature reveals that Trichoderma, has been repeatedly found. The occurrence of a great number of airborne fungi emphasizes the importance of studying airborne fungi that the climate of tropical areas supports the growth of airborne fungi, resulting in high levels of fungal spores in the air, which can increase the incidence of allergic respiratory diseases related to these fungi.

\section{REFERENCES}

Agarwal M.K., and Shivpuri D.N. 1974. Fungus spores- their role in respiratory allergy. Advances in Pollen Spore Research, 1: 78-128.

Gravesen S. 1972. Identification and quantification of indoor airborne microfungi during 12 months from 44 Danish homes. Acta Allergol., 27: 337-354.

Tilak S.T., and Babu M. 1983.Aerobiology of Pyricularia leaf sport diseases of bajra in relation of weather condition. Poll Res J., 4: 79-86.

Greicy Kiel. Christine C., Gaylarde. 2007. Diversity of tolerant culturable aerobic microorganisms of historic buildings in southern Brazil. W J of Microbiology and Biotech, 23(3): 303.

Morales J. Gonzaler F.J., Minero M., Carrasco V.M., Orgalla P., Candau. 2006.Airborne basidiospores in the atmosphere of Seville (south Spain). Aerobiologia, 14(1): 59.

Adhikari S., Bhattacharya and Chanda S. 1996.Aerobiology and allergenicity of indoor fungal spores in Calcutta during summer months. Indian Journal of Allergy and Applied Immunology, 10(1):11-19.

Devi A.P., Singh S.M., and N.I., Singh. 2012. Airborne fungal diversity in saw mills before and after flood in Imphal, Proc. Biodiversity status and conservation strategies with reference tone India, Manipur University, Manipur, India, 119-123.

Ayangbimpe G.M., Wapwera S.D., and Kuchin D.2010. Indoor air mycoflora of residential dwellings in Jos metropolis. African Health Sciences, 10(2):172 -176.

Banerjee U.C., Weber J., Ruffin and Banerjee S. 1987. Airborne fungi survey of some residences in Durham, North Carolina, USA: gravity settling culture plate method. Grana, 26, 103-108.

Noble W.C., and Clayton Y.M. 1963. Fungi in the air of hospital wards. Journal of General Microbiology, 32: $397-402$.

Baitule S.J., and Saoji A.A.2002. Aerobiological studies of allergenic Importance of the slum areas of Mumbai. Indian $J$ Allergy Asthama Immunol., 16(1): 55-71. 
ISSN 2393-9257

Table- 1 : Fungal airspora and their contribution (\%) in the indoor air

\begin{tabular}{|c|c|c|c|c|c|}
\hline \multirow[t]{2}{*}{ S.No. } & \multirow[t]{2}{*}{ Spores } & \multicolumn{2}{|c|}{2012} & \multicolumn{2}{|c|}{2013} \\
\hline & & $\begin{array}{c}\text { Abundance } \\
(\%)\end{array}$ & $\begin{array}{c}\text { Frequency } \\
(\%)\end{array}$ & $\begin{array}{c}\text { Abundance } \\
(\%)\end{array}$ & $\begin{array}{c}\text { Frequency } \\
(\%)\end{array}$ \\
\hline 1 & Alternaria & 100.00 & 0.16 & 100.00 & 0.20 \\
\hline 2 & Basidiospores & 100.00 & 1.60 & 100.00 & 3.15 \\
\hline 3 & Biospora & 83.33 & 0.033 & 83.33 & 0.040 \\
\hline 4 & Curvularia & 100.00 & 1.65 & 100.00 & 3.17 \\
\hline 5 & Chaetomium & 100.00 & 5.00 & 100.00 & 0.028 \\
\hline 6 & Sclerotium & 100.00 & 0.234 & 100.00 & 0.235 \\
\hline 7 & Trichoderma & 100.00 & 1.986 & 100.00 & 0.245 \\
\hline 8 & Epicoccum & 90.00 & 0.30 & 90.00 & 0.30 \\
\hline 9 & Aspergillus & 100.00 & 13.98 & 100.00 & 14.00 \\
\hline 10 & Mucor & 90.00 & 5.43 & 100.00 & 5.67 \\
\hline 11 & Rhizopus & 100.00 & 4.50 & 100.00 & 4.39 \\
\hline 12 & Cladosporium & 100.00 & 2.50 & 100.00 & 2.66 \\
\hline 13 & Helminthosporium & 89.00 & 1.00 & 90.00 & 0.99 \\
\hline 14 & Nigrospora & 100.00 & 3.00 & 100.00 & 3.12 \\
\hline 15 & Periconia & 89.00 & 0.23 & 89.00 & 0.99 \\
\hline
\end{tabular}

